\title{
KOEFISIEN KORELASI BEBERAPA HIMPUNAN KABUR
}

\author{
AL RIFQI RAHMAD PUTRA \\ Program Studi S1 Matematika, \\ Fakultas Matematika dan Ilmu Pengetahuan Alam, Universitas Andalas, \\ Kampus UNAND Limau Manis Padang, Indonesia, \\ email: alrifqi499552@gmail.com
}

\begin{abstract}
Abstrak. Teori himpunan kabur (fuzzy set) telah diperkenalkan oleh Zadeh pada tahun 1965, dimana teori ini dapat menjadi alternatif yang lebih baik dalam mencari solusi permasalahan yang mengandung ketidakpastian. Kemudian semakin berkembang ilmu pengetahuan, maka semakin banyak bentuk umum dari himpunan kabur (fuzzy set/FS) yang diusulkan dan dikembangkan, diantaranya ada himpunan kabur intuisionistik (Intuitionistic Fuzzy Sets/IFS), himpunan kabur hesitant (Hesitant Fuzzy Sets (HFS)), dan himpunan kabur dual hesitant (Dual Hesitant Fuzzy Sets (DHFS)). Pada penelitian ini akan dikaji tentang koefisien korelasi antara himpunan kabur intuisionistik, koefisien korelasi himpunan kabur hesitant dan koefisien korelasi himpunan kabur dual hesitant. Koefisien korelasi bertujuan untuk mengukur tingkat keeratan hubungan antara dua variabel atau parameter. Kemudian koefisien yang diperoleh di antara dua DHFS dengan menggunakan konsep dari statistik, formulanya dikembangkan untuk koefisien korelasi $r_{1}$ untuk keanggotaan dan $r_{2}$ untuk bukan keanggotaan. Selanjutnya rata-rata dari $r_{1}$ dan $r_{2}$ menentukan koefisien korelasi $r$ di antara data yang diwakili oleh dua DHFS.

Kata Kunci: Koefisien korelasi, himpunan kabur, himpunan kabur intusionistik, himpunan kabur hesitant, himpunan kabur dual hesitant, koefisien korelasi himpunan kabur intuisionistik, koefisien korelasi himpunan kabur hesitant, koefisien korelasi himpunan kabur dual hesitant
\end{abstract}

$\begin{array}{lll}\text { Diterima } & : & 26 \text { Juli } 2018 \\ \text { Direvisi } & : & 17 \text { September } 2018 \\ \text { Dipublikasikan } & : & 21 \text { Desember } 2018\end{array}$

\section{Pendahuluan}

Teori himpunan kabur (fuzzy set) telah diperkenalkan oleh Zadeh [18] pada tahun 1965, dimana teori ini dapat menjadi alternatif yang lebih baik dalam mencari solusi permasalahan yang mengandung ketidakpastian. Kemudian semakin berkembang ilmu pengetahuan, maka semakin banyak bentuk umum dari himpunan kabur ( fuzzy set/FS) yang diusulkan dan dikembangkan, diantaranya ada himpunan kabur intuisionistik (Intuitionistic Fuzzy Sets/IFS) [1], himpunan kabur multisets [11] dan himpunan kabur hesitant (Hesitant Fuzzy Sets (HFS)) [14].

Korelasi digunakan untuk menyimpulkan perubahan pada satu variabel yang terhubung dengan variabel lain [12]. Kemudian koefisien korelasi dipergunakan secara luas di bidang statistik untuk melihat hubungan dua variabel yang terdapat dalam data yang dimiliki. Terkadang data yang dikumpulkan berhubungan dengan 
masalah di kehidupan sehari-hari yang nilainya tidak pasti. Untuk menghadapi masalah ini, konsep dari korelasi telah diperluas ke korelasi kabur oleh berbagai peneliti, seperti Chiang dan Lin [4], Gantung dan Hwan [3], Liu dan Kao [10] dan lainnya. Pada [7] telah diperoleh formula dari koefisien korelasi kabur, yang didefinisikan pada domain dari himpunan kabur. Nilai dari koefisien korelasi kabur terletak pada interval $[-1,1]$, yang memiliki arti yang sama seperti koefisien korelasi pada statistik.

Pada 2012, Zhu, dkk [19] memperluas konsep HFS ke Himpunan kabur dual hesitant (Dual Hesitant Fuzzy Sets (DHFS)). Oleh karena itu, pada penelitian ini akan dikaji kembali apa yang dibahas pada [16] yaitu tentang koefisien korelasi himpunan kabur intuisionistik, koefisien korelasi himpunan kabur hesitant dan koefisien korelasi himpunan kabur dual hesitant. Kemudian koefisien korelasi yang diperoleh di antara dua DHFS dengan menggunakan konsep dari statistik, formulanya dikembangkan untuk koefisien korelasi $r_{1}$ untuk keanggotaan dan $r_{2}$ untuk bukan keanggotaan. Selanjutnya rata-rata dari $r_{1}$ dan $r_{2}$ menentukan koefisien korelasi $r$ di antara data yang diwakili oleh dua DHFS.

\section{Landasan Teori}

\subsection{Koefisien Korelasi}

Koefisien korelasi antara dua peubah $\mathrm{X}$ dan $\mathrm{Y}$ yang dinotasikan dengan $r_{X Y}$ untuk $n$ pasangan contoh pengamatan $\left(x_{i}, y_{i}\right) ; i=1,2, \cdots, n$ dapat dihitung dengan menggunakan rumus berikut [17].

$$
r_{x y}=\frac{n \sum_{i=1}^{n}\left(x_{i} y_{i}\right)-\left(\sum_{i=1}^{n}\left(x_{i}\right) \cdot \sum_{i=1}^{n}\left(y_{i}\right)\right)}{\sqrt{n \sum_{i=1}^{n}\left(x_{i}\right)^{2}-\left(\sum_{i=1}^{n}\left(x_{i}\right)\right)^{2}} \cdot \sqrt{n \sum_{i=1}^{n}\left(y_{i}\right)^{2}-\left(\sum_{i=1}^{n}\left(y_{i}\right)\right)^{2}}},
$$

dimana nilai koefisien korelasi berada pada interval $[-1,1]$.

\subsection{Himpunan Kabur (Fuzzy Sets)}

Himpunan kabur (fuzzy sets) pertama kali diperkenalkan oleh Zadeh dari Universitas California, Berkeley pada tahun 1965. Himpunan kabur digunakan untuk mengantisipasi kelemahan dari himpunan klasik. Seberapa besar elemennya dalam himpunan tersebut dilihat dari nilai keanggotaannya. Sebelum himpunan kabur muncul, dikenal sebuah himpunan klasik atau yang seringkali disebut himpunan tegas ( crisp sets). Himpunan klasik adalah himpunan dengan nilai keanggotaan 1 (satu) jika termasuk dalam anggota atau 0 (nol) jika tidak termasuk dalam anggota himpunan. Sedangkan himpunan kabur adalah himpunan dengan bobot keanggotaan pada suatu himpunan berada pada selang $[0,1]$.

Definisi 2.1. [5] Misalkan A adalah himpunan. Suatu himpunan kabur (fuzzy sets) $X$ atas $A$ dapat didefinisikan sebagai :

$$
X=\left\{\left(x, \mu_{A}(x)\right) \mid x \in A\right\}
$$

dimana $\mu_{A}: A \rightarrow[0,1]$ disebut fungsi keanggotaan $X$ atas $A$. 


\subsection{Himpunan Kabur Intuisionistik (Fuzzy Intuitionistic Sets)}

Definisi 2.2. [13] Misalkan $X$ adalah himpunan semesta yang tak kosong. Himpunan kabur intuisionistik (IFS) $A^{I}$ atas $X$ adalah :

$$
A^{I}=\left\{<x, \mu_{A^{I}}(x), v_{A^{I}}(x)>\mid x \in X\right\},
$$

dimana $\mu_{A^{I}}, v_{A^{I}}: X \rightarrow[0,1]$ berturut-turut menyatakan fungsi keanggotaan dan fungsi non-keanggotaan dari $x \in X$ pada himpunan $A^{I}$, dimana $0 \leq \mu_{A^{I}}(x)+$ $v_{A^{I}}(x) \leq 1$ untuk setiap $x \in X$.

\subsection{Himpunan Kabur Hesitant (Hesitant Fuzzy Sets)}

Definisi 2.3. [13] Misalkan $X=\left\{x_{1}, x_{2}, \cdots, x_{n}\right\}$ adalah himpunan, maka himpunan kabur hesitant (HFS) $H$ dari $X$ adalah :

$$
H=\{<x, h(x)>\mid x \in X\}
$$

dimana $h(x)$ disebut element kabur hesitant (Hesitant Fuzzy Element) (HFE), yang menunjukkan derajat-derajat keanggotaan yang memungkinkan dari elemen $x \in X$ pada himpunan $H$.

Torra [15] mendefinisikan beberapa himpunan kabur hesitant khusus sebagai berikut.

(i) Empty Set : $h(x)=\{0\}$ untuk semua $x \in X$;

(ii) Full Set : $h(x)=\{1\}$ untuk semua $x \in X$;

(iii) Complete ignorance:: $h(x)=[0,1]$ untuk semua $x \in X$;

(iv) Set for non-sense:: $h(x)=\phi$ untuk semua $x \in X$.

Batas bawah dan batas atas dari himpunan kabur hesitant $\mathrm{H}$ dapat didefinisikan dalam hal HFE $h(x)$ sebagai berikut.

$$
\begin{aligned}
& \text { batas bawah }: h^{-}(x)=\min h(x) ; \\
& \text { batas atas }: h^{+}(x)=\max h(x) .
\end{aligned}
$$

Dengan menggunakan batas bawah $h^{-}(x)$ dan batas atas $h^{+}(x)$ dapat dibuktikan bahwa himpunan kabur intuisionistik adalah kasus khusus dari HFS.

Suatu himpunan kabur intuisionistik $A_{i}=\left\{\left\langle x, \mu_{A}(x), v_{A}(x)\right\rangle\right\}$ dapat didefinisikan dalam hal pasangan fungsi $h^{-}(x)$ dan $h^{+}(x)$ sebagai berikut.

$$
A_{i}=\left\{<x, \mu_{A}(x), v_{A}(x)>\right\}=\left\{<x, h^{-}(x), 1-h^{+}(x)>\right\} .
$$

Berikut diberikan definisi dari komplemen HFS. Untuk HFS dengan $h(x)$ sebagai HFE nya, Torra [15] mendefinisikan komplemen dari $h(x)$ sebagai berikut.

$$
h^{c}(x)=\bigcup_{m \in h(x)}\{1-m\} .
$$




\section{Himpunan Kabur Dual Hesitant}

Zhu dkk [20] memperpanjang konsep HFS untuk menghasilkan himpunan kabur dual hesitant (DHFS). Mereka mendefinisikan DHFS dalam dua fungsi yaitu fungsi keanggotaan dan fungsi non-keanggotaan. Suatu DHF pada $X$ dapat ditulis sebagai $D=\{<x, h(x), g(x)>\mid x \in X\}$, dimana $h(x)$ dan $g(x)$ mewakili fungsi keanggotaan dan fungsi non-keanggotaan dari $x \in X$ pada $\mathrm{D}$ yang merupakan dua himpunan dengan nilai-nilai pada $[0,1]$ dengan ketentuan sebagai berikut.

$0 \leq m, n \leq 1,0 \leq m^{+}+n^{+} \leq 1$, dimana $m \in h(x), n \in g(x), m^{+}=h^{+}(x)$, dan $n^{+}=g^{+}(x)$.

Untuk lebih mudah, pasangan $d(x)=\{h(x), g(x)\}$ disebut elemen dual hesitant (DHFE), dinotasikan sebagai $d=\{h, g\}$ dengan kondisi yang sama disebutkan di atas.

Seperti dengan HFS, Zhu dkk [19] juga mendefinisikan beberapa DHFEs khusus:

(i) Complete uncertainty: $d=\{\{0\},\{1\}\}$.

(ii) Complete certainty: $d=\{\{1\},\{0\}\}$.

(iii) Complete ill known (all is possible): $d=\left\{\left\{x_{i}\right\},\left\{y_{i}\right\}\right\}$ ( $x_{i}, y_{i}$ berada dalam $[0,1]$ dan $i=1,2, \cdots, n)$.

(iv) Nonsensical element: $d=\{\phi, \phi\}(h=\{0\}, g=\{0\})$.

Selain itu, dapat diamati bahwa untuk $d \neq\{0\}$, jika $h$ dan $g$ mencapai hanya satu nilai masing-masing $m$ dan $n$, dengan kondisi $m+n<1$ maka DHFS merupakan suatu IFS. Juga, jika $h$ dan $g$ mencapai hanya satu nilai masing-masing $m$ dan $n$, dengan kondisi $m+n=1$ dan $g \neq\{0\}$ maka DHFS merupakan suatu FS. Untuk $g=\{0\}$ dan $h \neq\{0\}$ Suatu DHFS merupakan suatu HFS.

Atanassov [1] dan Torra [14] mengembangkan himpunan teori operasi yang berbeda pada masing-masing IFS dan HFS. Demikian pula, Zhu, dkk [19] memperkenalkan himpunan teori operasi yang berbeda pada DHFS sebagai berikut.

$$
d^{c}= \begin{cases}\bigcup_{m \in h, n \in g}\{\{n\},\{m\}\} & , \text { jika } g \neq\{0\} \text { dan } h \neq\{0\}, \\ \bigcup_{m \in h}\{\{1-m\},\{\{0\}\}\} & , \text { jika } g=\{0\} \text { dan } h \neq\{0\}, \\ \bigcup_{n \in g}\{\{\{0\}\},\{1-n\}\} & , \text { jika } h=\{0\} \text { dan } g \neq\{0\} .\end{cases}
$$

\section{Pembahasan}

\subsection{Koefisien Korelasi dari DHFS}

Sebelum mendefinisikan koefisien korelasi dari DHFS, akan didefisikan koefisien korelasi dari IFS dan HFS.

\subsubsection{Koefisien Korelasi dari IFS}

Banyak peneliti yang telah membahas tentang koefisien korelasi IFS. Misalkan $X=$ $\left\{x_{1}, x_{2}, \cdots, x_{n}\right\}$ adalah himpunan semesta, dan $F^{I}$ merupakan himpunan kabur intuisionistik yang berisi semua IFS terhadap $X$. Untuk setiap dua IFS A dan B, Szmidt, dkk [13] mendefinisikan koefisien korelasi sebagai berikut.

$$
r(A, B)=\frac{1}{3}\left(r_{1}(A, B)+r_{2}(A, B)+r_{3}(A, B)\right),
$$


dimana

$$
\begin{aligned}
& r_{1}(A, B)=\frac{\sum_{i=1}^{n}\left(\mu_{A}\left(x_{i}\right)-\bar{\mu}_{A}\right)\left(\mu_{B}\left(x_{i}\right)-\bar{\mu}_{B}\right)}{\left(\sum_{i=1}^{n}\left(\mu_{A}\left(x_{i}\right)-\bar{\mu}_{A}\right)^{0.5} \sum_{i=1}^{n}\left(\mu_{B}\left(x_{i}\right)-\bar{\mu}_{B}\right)^{0,5}\right)^{0,5}} \\
& r_{2}(A, B)=\frac{\sum_{i=1}^{n}\left(v_{A}\left(x_{i}\right)-\bar{v}_{A}\right)\left(v_{B}\left(x_{i}\right)-\bar{v}_{B}\right)}{\left(\sum_{i=1}^{n}\left(v_{A}\left(x_{i}\right)-\bar{v}_{A}\right)^{0,5} \sum_{i=1}^{n}\left(v_{B}\left(x_{i}\right)-\bar{v}_{B}\right)^{0,5}\right)^{0,5}} \\
& r_{3}(A, B)=\frac{\sum_{i=1}^{n}\left(\pi_{A}\left(x_{i}\right)-\bar{\pi}_{A}\right)\left(\pi_{B}\left(x_{i}\right)-\bar{\pi}_{B}\right)}{\left(\sum_{i=1}^{n}\left(\pi_{A}\left(x_{i}\right)-\bar{\pi}_{A}\right)^{0,5} \sum_{i=1}^{n}\left(\pi_{B}\left(x_{i}\right)-\bar{\pi}_{B}\right)^{0,5}\right)^{0,5}}
\end{aligned}
$$

dengan, $\mu_{A}, \mu_{B}$ adalah fungsi keanggotaan, $v_{A}, v_{B}$ adalah fungsi non keanggotaan dan, $\pi_{A}, \pi_{B}$ adalah nilai keragu-raguan yang didefinisikan sebagai berikut. $\pi=1-$ $\mu-v, \bar{\mu}_{A}=\frac{1}{n} \sum_{i=1}^{n} \mu_{A}\left(x_{i}\right), \bar{\mu}_{B}=\frac{1}{n} \sum_{i=1}^{n} \mu_{B}\left(x_{i}\right), \bar{v}_{A}=\frac{1}{n} \sum_{i=1}^{n} v_{A}\left(x_{i}\right), \bar{v}_{B}=\frac{1}{n} \sum_{i=1}^{n} v_{B}\left(x_{i}\right)$, $\bar{\pi}_{A}=\frac{1}{n} \sum_{i=1}^{n} \pi_{A}\left(x_{i}\right), \bar{\pi}_{B}=\frac{1}{n} \sum_{i=1}^{n} \pi_{B}\left(x_{i}\right)$ merupakan variabel kabur intuisionistik A dan B.

\subsubsection{Koefisien Korelasi dari HFS}

Chen dkk [3] memperkenalkan korelasi HFS didefinisikan atas himpunan semesta. Misalkan $A=\left\{\left\langle x_{i}, h_{A}\left(x_{i}\right)\right\rangle: x_{i} \in X, i=1,2,3, \cdots, n\right\}$ dan $B=\left\{\left\langle x_{i}, h_{B}\left(x_{i}\right)\right\rangle\right.$ : $\left.x_{i} \in X, i=1,2,3, \cdots, n\right\}$ menjadi dua HFS yang didefinisikan atas nilai semesta $X=\left\{x_{1}, x_{2}, \cdots, x_{n}\right\}$. Chen, dkk [3] mengamati bahwa nilai-nilai HFE biasanya disusun berurutan.

Untuk $h$ dari HFE, digunakan permutasi $\sigma:(1,2, \cdots, n) \longrightarrow(1,2, \cdots, n)$ memenuhi kondisi $h_{\sigma(i)} \geqslant h_{\sigma(i+1)}$, dimana $i=1,2, \cdots, n-1$ dan $h_{\sigma(j)}$ adalah nilai terbesar ke-j dari semua $h$.

Selain itu, dengan nilai permutasi yang berbeda mungkin nilai HFS akan berbeda. Untuk mengatasi masalah ini, diasumsikan $l_{i}=\max \left\{l\left(h_{A}\left(x_{i}\right)\right), l\left(h_{B}\left(x_{i}\right)\right)\right\}$ untuk setiap $x_{i} \in X$, dimana $l\left(h_{A}\left(x_{i}\right)\right)$ dan $l\left(h_{B}\left(x_{i}\right)\right)$ merupakan banyak elemen dari dua HFEs masing-masing $h_{A}\left(x_{i}\right)$ dan $h_{B}\left(x_{i}\right)$. Jika $l\left(h_{A}\left(x_{i}\right)\right) \neq l\left(h_{B}\left(x_{i}\right)\right)$; untuk membuat $l\left(h_{A}\left(x_{i}\right)\right)$ dan $l\left(h_{B}\left(x_{i}\right)\right)$ memiliki jumlah elemen yang sama, dengan cara menambahkan elemen terkecil pada HFE yang memiliki jumlah elemen yang lebih sedikit. Korelasi dua HFS dari A dan B, didefinisikan sebagai berikut.

$$
C_{H F S}(A, B)=\sum_{i=1}^{n}\left(\frac{1}{l_{i}} \sum_{j=1}^{l_{i}} h_{A \sigma(j)}\left(x_{i}\right) h_{B \sigma(j)}\left(x_{i}\right)\right) \text {. }
$$


Koefisien korelasi dari dua HFS dari A dan B yaitu :

$$
\begin{aligned}
\rho_{H F S}(A, B) & =\frac{C_{H F S}(A, B)}{\sqrt{C_{H F S}(A, A) C_{H F S}(B, B)}} \\
& =\frac{\sum_{i=1}^{n}\left(\frac{1}{l_{i}} \sum_{j=1}^{l_{i}} h_{A \sigma(j)}\left(x_{i}\right) h_{B \sigma(j)}\left(x_{i}\right)\right)}{\sqrt{\left(\sum_{i=1}^{n}\left(\frac{1}{l_{i}} \sum_{j=1}^{l_{i}} h_{A \sigma(j)}^{2}\left(x_{i}\right)\right)\right)\left(\sum_{i=1}^{n}\left(\frac{1}{l_{i}} \sum_{j=1}^{l_{i}} h_{B \sigma(j)}^{2}\left(x_{i}\right)\right)\right)}} .
\end{aligned}
$$

Teorema koefisien korelasi $\rho_{H F S}(A, B)$ memenuhi kondisi dibawah ini :

(1) $\rho_{H F S}(A, B)=\rho_{H F S}(B, A)$;

(2) $0 \leqslant \rho_{H F S}(A, B) \leqslant 1$;

(3) $\rho_{H F S}(A, B)=1$ jika $A=B$.

\subsubsection{Koefisien Korelasi dari DHFS}

Misalkan

$$
\begin{aligned}
& D_{A}=\left\{\left\langle x_{i}, h_{A}\left(x_{i}\right), g_{A}\left(x_{i}\right)\right\rangle: x_{i} \in X\right\}, \text { dan } \\
& D_{B}=\left\{\left\langle x_{i}, h_{B}\left(x_{i}\right), g_{B}\left(x_{i}\right)\right\rangle: x_{i} \in X\right\}
\end{aligned}
$$

adalah dua DHFS yang didefinisikan oleh himpunan semesta $X=\left\{x_{1}, x_{2}, \cdots, x_{n}\right\}$. Dapat disimpulkan bahwa nilai-nilai keanggotaan/ kenon-anggotaan dari DHFE umumnya tidak berurutan. Menurut Chen, dkk [3] untuk lebih memudahkan, nilainilai tersebut dapat disusun dalam urutan naik/turun dengan menggunakan dua permutasi

$$
\begin{aligned}
& p_{1}:(1,2, \cdots, n) \longrightarrow(1,2, \cdots, n), \\
& p_{2}:(1,2, \cdots, n) \longrightarrow(1,2, \cdots, n)
\end{aligned}
$$

yang memenuhi syarat $h_{p_{1}(i)} \geqslant h_{p_{1}(i+1)}$ dan $g_{p_{2}(i)} \geqslant g_{p_{2}(i+1)}$ untuk $i=1,2, \cdots, n$.

Mirip dengan HFS, banyak nilai dari beberapa DHFE mungkin berbeda. Untuk membuat beberapa DHFE tersebut sama, yaitu dengan menambahkan nilai terkecil dari tiap-tiap $h(x)$ dan nilai terbesar dari tiap-tiap $g(x)$. Untuk itu, misalkan $l_{i}=\max \left\{l\left(h_{A}\left(x_{i}\right)\right),\left(h_{B}\left(x_{i}\right)\right)\left(g_{A}\left(x_{i}\right)\right)\left(g_{B}\left(x_{i}\right)\right)\right\}$ untuk setiap $x_{i} \in X$ dimana $l\left(h_{A}\left(x_{i}\right)\right), l\left(h_{B}\left(x_{i}\right)\right), l\left(g_{A}\left(x_{i}\right)\right)$, dan $l\left(g_{B}\left(x_{i}\right)\right)$ menyatakan banyak nilai dari $h_{A}\left(x_{i}\right)$, $h_{B}\left(x_{i}\right), g_{A}\left(x_{i}\right)$ dan $g_{B}\left(x_{i}\right)$ masing-masingnya. Jika $l_{i}\left(h_{A}\left(x_{i}\right)\right)<l_{i}\left(h_{B}\left(x_{i}\right)\right)$ maka nilai terkecil dari $h_{B}\left(x_{i}\right)$ akan ditambahkan ke $h_{A}\left(x_{i}\right)$. Serupa dengan kasus di atas, jika $\left.l\left(g_{A}\left(x_{i}\right)\right)<l\left(g_{B}\left(x_{i}\right)\right)\right)$ maka nilai terbesar dari $g_{B}\left(x_{i}\right)$ akan ditambahkan ke $g_{A}\left(x_{i}\right)$ untuk setiap $x_{i} \in X$. Sekarang, suatu metode untuk menentukan korelasi antara dua DHFS, $D_{A}$ dan $D_{B}$, diberikan sehingga diperoleh kekuatan relatif yang positif, bisa juga negatif, antara $D_{A}$ dan $D_{B}$. Koefisien korelasi "r" antara dua DHFS, $D_{A}$ dan $D_{B}$, dapat didefinisikan sebagai berikut :

$$
r\left(D_{A}, D_{B}\right)=\frac{1}{2}\left(r_{1}\left(D_{A}, D_{B}\right)+r_{2}\left(D_{A}, D_{B}\right)\right)
$$


dimana

$$
r_{1}\left(D_{A}, D_{B}\right)=\frac{\sum_{i=1}^{n}\left[\left(\frac{1}{l_{i}} \sum_{j=1}^{l_{i}}\left(h_{A p_{1}(j)}\left(x_{i}\right)-\bar{h}_{A}\right)\right) \cdot\left(\frac{1}{l_{i}} \sum_{j=1}^{l_{i}}\left(h_{B p_{1}(j)}\left(x_{i}\right)-\bar{h}_{B}\right)\right)\right]}{\sqrt{\sum_{i=1}^{n}\left(\frac{1}{l_{i}} \sum_{j=1}^{l_{i}}\left(h_{A p_{1}(j)}\left(x_{i}\right)-\bar{h}_{A}\right)\right)^{2}} \cdot \sqrt{\sum_{i=1}^{n}\left(\frac{1}{l_{i}} \sum_{j=1}^{l_{i}}\left(h_{B p_{1}(j)}\left(x_{i}\right)-\bar{h}_{B}\right)\right)^{2}}}
$$

dan

$$
r_{2}\left(D_{A}, D_{B}\right)=\frac{\sum_{i=1}^{n}\left[\left(\frac{1}{l_{i}} \sum_{j=1}^{l_{i}}\left(g_{A p_{1}(j)}\left(x_{i}\right)-\bar{g}_{A}\right)\right) \cdot\left(\frac{1}{l_{i}} \sum_{j=1}^{l_{i}}\left(g_{B p_{1}(j)}\left(x_{i}\right)-\bar{g}_{B}\right)\right)\right]}{\sqrt{\sum_{i=1}^{n}\left(\frac{1}{l_{i}} \sum_{j=1}^{l_{i}}\left(g_{A p_{1}(j)}\left(x_{i}\right)-\bar{g}_{A}\right)\right)^{2}} \cdot \sqrt{\sum_{i=1}^{n}\left(\frac{1}{l_{i}} \sum_{j=1}^{l_{i}}\left(g_{B p_{1}(j)}\left(x_{i}\right)-\bar{g}_{B}\right)\right)^{2}}} .
$$

Sebagai tambahan

$$
\bar{h}_{A}=\frac{1}{n} \sum_{i=1}^{n}\left(\frac{1}{l_{i}} \sum_{j=1}^{l_{i}} h_{A p_{1}(j)}\left(x_{i}\right)\right)
$$

dan

$$
\bar{h}_{B}=\frac{1}{n} \sum_{i=1}^{n}\left(\frac{1}{l_{i}} \sum_{j=1}^{l_{i}} h_{B p_{1}(j)}\left(x_{i}\right)\right),
$$

dan

$$
\bar{g}_{A}=\frac{1}{n} \sum_{i=1}^{n}\left(\frac{1}{l_{i}} \sum_{j=1}^{l_{i}} g_{A p_{1}(j)}\left(x_{i}\right)\right)
$$

dan

$$
\bar{g}_{B}=\frac{1}{n} \sum_{i=1}^{n}\left(\frac{1}{l_{i}} \sum_{j=1}^{l_{i}} g_{B p_{1}(j)}\left(x_{i}\right)\right) .
$$

Teorema 4.1. Koefisien korelasi " $r$ " antara dua DHFS, $D_{A}$ dan $D_{B}$, memenuhi syarat-syarat berikut :

(i) $r\left(D_{A}, D_{B}\right)=r\left(D_{B}, D_{A}\right)$;

(ii) $\left|r\left(D_{A}, D_{B}\right)\right| \leq 1$;

(iii) $r\left(D_{A}, D_{B}\right)=1$ jika $A=B$.

\section{Kesimpulan}

Pada makalah ini, dengan menggunakan konsep koefisien korelasi pada statistika matematika pada interval $[-1,1]$, rumus untuk koefisien korelasi antara dua DHFS diperoleh. Koefisien korelasi yang didiskusikan, bertujuan untuk mengukur hubungan antara dua DHFS dan mengindikasikan kuat-lemahnya hubungan koefisien korelasi tersebut, baik itu positif maupun negatif. Bagian penting dari makalah ini adalah kedua nilai keanggotaan dan kenon-anggotaan diperhitungkan untuk mengevaluasi korelasi antara dua variabel/parameter. Sebagaimana DHFS 
adalah himpunan luas yang meliputi beberapa himpunan yang telah ada, seperti himpunan kabur, himpunan kabur intuisionistik, dan himpunan kabur hesitant, dan lain-lain, Suatu koefisien korelasi yang lebih realistis dan akurat antara parameterparameter berbeda telah diperoleh.

\section{Daftar Pustaka}

[1] Atanassov, K. 1983. Intuitionistic Fuzzy Sets. VII ITKR Session. Sofia Centr. Sci.-Techn. Libr. of Bulg. Acad. of Sci.,in Bulgarian. 84 : 1697.

[2] Bustince, H dan P. Burillo. 1995. Correlation of interval-valued intuitionistic fuzzy sets, Fuzzy Sets Syst. 74 : 237-244.

[3] Chen, N dan Z. Xu, M. Xia. 2013. Correlation coefficients of hesitant fuzzy sets dan their applications to clustering analysis. Appl. Math. Model. 37 : 2197-2211.

[4] Chiang, D.A dan N.P. Lin. 1999. Correlation of fuzzy sets. Fuzzy Sets Syst. 102 : 221-226.

[5] Gersternkorn, T dan J. Manko. 1991. Correlation of intuitionistic fuzzy sets, Fuzzy Sets Syst. 44 : 39-43.

[6] Hong, D.H dan S.Y. Hwang. 1996. A note on the correlation of fuzzy numbers. Fuzzy Sets Syst. 79 : 401-402.

[7] Hong, D.H dan S.Y. Hwang. 1995. Correlation of intuitionistic fuzzy sets in probability spaces. Fuzzy Sets Syst. 75 : 77-81.

[8] Hung, W.L. 2001. Using statistical viewpoint in developing correlation of intuitionistic fuzzy sets. Int. J. Uncertainty Fuzziness Knowledge-Based Syst. 9 : $509-516$.

[9] Hung, W.L dan J.W. Wu. 2002. Correlation of intuitionistic fuzzy sets by centroid method, Inf. Sci. $144: 219-225$.

[10] Liu, S.T dan C. Kao. 2002. Fuzzy measures for correlation coefficient of fuzzy numbers. Fuzzy Sets Syst. 128 : 267-275.

[11] Miyamoto, S.2005. Remarks on basics of fuzzy sets dan fuzzy multisets. Fuzzy Set Syst. 156 : 427 - 431.

[12] Rodgers, J.L dan W. Alan Nicewander. 1988. Thirteen ways to look at the correlation coefficient. Am. Statist. 42 : 59-66.

[13] Szmidt, E., J. Kacprzyk dan P. Bujnowski. 2011. Pearsons coefficient between intuitionistic fuzzy sets, Fifteenth Int. Conf. on IFS, Burgas. 11-12.

[14] Torra, V dan Y. Narukawa. 2009. On hesitant fuzzy sets dan decision. The 18th IEEE international conference on fuzzy systems, Jeju Island, Korea. 1378-1382.

[15] Torra, V. 2010.Hesitant fuzzy sets. Int. J. Intell. Syst. 25 : 529-539.

[16] Tyagi, S. K. 2015. Correlation coefficient of dual hesitant fuzzy sets dan its applications. Applied Mathematical Modelling. 39 : 7082-7092.

[17] Walpole, R. E. 1988. Pengantar Statistika. PT Gramedia Utama. 3 : 371.

[18] Zadeh, L.A. 1965. Fuzzy sets. Inf. Control. 8 : 338-353.

[19] Zeng, W dan H. Li. 2007. Correlation coefficient of intuitionistic fuzzy sets, J. Ind. Eng. Int. 3 : 33-40.

[20] Zhu, B., Z. Xu, dan M. Xia. 2012. Dual hesitant fuzzy sets. J. Appl. Math. 